\title{
SOCIEDADE MIDIATIZADA: AS \\ AFETAÇÕES DO CAMPO DOS MEDIA NA CONTEMPORANEIDADE
}

\author{
MEDIATED SOCIETY: THE AFFECTATIONS OF THE FIELD OF \\ MEDIA IN CONTEMPORARY
}

\begin{abstract}
DAIANA STASIAK
Relações Públicas, Mestre em Comunicação Midiática (UFSM); Doutoranda do PPGCom da Universidade de Brasília (UnB). Professora Assistente da Faculdade de Comunicação e Biblioteconomia (FACOMB) da Universidade Federal de Goiás (UFG).daiastasiak@gmail.com
\end{abstract}

\section{RESUMO}

Sob o contexto da sociedade midiatizada, advinda com as novas tecnologias de comunicação e informação, o artigo objetiva questionar o conceito de campo dos media construído por Rodrigues (1990) que concebe os meios ainda como um subsistema representacional e linear. Os questionamentos ocorrem a partir de uma demanda atual que demonstra a afetação entre mídias tradicionais (rádio, TV e impressos) e as possibilidades da internet que ocasionam transformações capazes de delinear novas perspectivas para os estudos da área da comunicação.

Palavras-chave: midiatização, campo dos media, convergência tecnológica

\section{ABSTRACT}

Under the context of mediated society, arising with the new technologies of communication and information, the paper aims to question the concept of field of the media constructed by Rodrigues (1990) which sees the media even as a linear subsystem and representational. The questions occur from a current demand which shows the affection between traditional media (radio, TV and print) and the possibilities of the Internet that can cause changes to outline new prospects for studies of the area of communication. Keywords: mediatisation, field of media, convergence technology

\section{RESUMEN}

Bajo el contexto de la sociedad mediatizada, que surgen con las nuevas tecnologías de comunicación e información, el documento tiene por objeto cuestionar el concepto de campo de los medios de comunicación construidos por Rodrigues (1990) que considera que los medios de comunicación, incluso como un subsistema lineal y de representación. Las preguntas se producen de una demanda actual, lo que 
demuestra el afecto entre los medios tradicionales (radio, televisión y prensa escrita) y las posibilidades de la Internet que puede causar cambios de esbozar nuevas perspectivas para los estudios del área de comunicación.

Palabras clave: mediatización, campo de los medios; convergencia tecnología

\section{Introdução}

A transformação do sistema representacional de visibilidade das mídias tradicionais para um sistema de interatividade entre emissores e receptores é um fenômeno advindo com as possibilidades da convergência tecnológica que modifica constantemente as lógicas de mediação da comunicação. Nesse contexto, o conceito de campo dos media exposto por Rodrigues (1990) pode ser alvo de algumas indagações. Por isso, o presente artigo objetiva trazer subsídios para compreender como as mídias afetam-se em suas práticas na contemporaneidade.

Rodrigues (1990) concebe os meios como um subsistema responsável por realizar certas funções sociais (entretenimento e vigilância, entre outras). Nessa perspectiva o campo dos media atuaria como mobilizador do debate público e da produção de sentidos entre os campos sociais, nele sujeitos e instituições disputariam a sua visibilidade através das representações veiculadas nos meios de comunicação tradicionais (rádio, televisão, revistas e jornais impressos) para obter legitimidade diante dos demais campos.

Acompanhamos a migração da palavra para a imagem, do discurso para a representação que levam a reflexões importan- tes sobre as transformações que os meios de comunicação protagonizaram na vida pessoal e social dos indivíduos. Assim, uma nova espécie de sociedade está surgindo e os meios de comunicação são questões cruciais nesse debate. Marc Augé (2006) define a sociedade atual como uma esfera na qual predominam o excesso de informações, o excesso de imagens e o excesso de individualismo. Fenômenos que, atrelados às novas tecnologias da comunicação, colocam os sujeitos diante da esfera do imediatismo e da instantaneidade e revelam a todos que o planeta, definitivamente, encolheu.

Esta breve introdução visa demonstrar um contexto no qual os fenômenos estão cada vez mais líquidos e entrecruzados, Bauman (2001). Nas questões pertinentes à mídia, as discussões tornam-se fundamentais para a compreensão de certos fenômenos, para tanto, o artigo subdivide-se em três partes principais, a primeira aborda as características do campo dos media a partir de Rodrigues (1990), a segunda tece considerações teóricas a respeito do processo de midiatização que permeia a sociedade e a terceira faz menção à convergência tecnológica e elucida alguns exemplos de afetações entre os meios de comunicação. Por fim 
buscamos entender o perfil midiático contemporâneo que abarca mídias lineares e reticulares em constante troca de informações e influências entre suas práticas cotidianas.

\section{Campo dos media}

Antes da existência da mídia, a visibilidade de um ator ou instituição se dava no local dos acontecimentos, não ultrapassando certos limites geográficos. Porém, o desenvolvimento dos meios de comunicação proporcionou um outro tipo de visibilidade e trouxe novas formas de controle social. Michel Foucault (1986), por exemplo, propõe a noção de visibilidade como a tecnologia de cada época que proporciona os regimes de luz, ou seja, a publicização das práticas discursivas dos domínios sociais.

A partir do século $\mathrm{XX}$, os problemas referentes à relação entre sociedade e comunicação parecem mais evidentes, pois os meios de comunicação adquirem centralidade na vida social. Eles assumem, progressivamente, um papel que vai além da veiculação de informações e tornam-se responsáveis pela produção de grande parte dos sentidos que circulam na sociedade.

Segundo Dominique Wolton (1996), antigamente cada universo social e cultural possuía seu sistema de legitimidade, de reconhecimento e de comunicação definidos, mas isto não interferia na sua presença no espaço público. Era mais importante para os campos sociais garantir a comunicação dentro das fronteiras de seu próprio meio do que no es- paço público, a convivência entre regras internas e externas aos campos era fundamental. Porém, com o passar dos anos, o avanço das tecnologias refletiu na esfera dos meios de comunicação e trouxe algumas modificações a essas lógicas. Conforme o Wolton:

é claro que ainda hoje as regras de legitimação continuam regidas pelas diversas comunidades parciais mas, o verdadeiro espaço de valorização se tornou o espaço público, ou seja, o espaço gerado pela lei do indivíduo e das mídias. A perda de autonomia e de credibilidade das legitimidades parciais reforçam o peso da lógica midiática (WOLTON, 1996, p. 221).

Os meios de comunicação formam uma esfera de comunicação com relativa autonomia. Segundo Rodrigues (1990, p.152), "campo dos media é a denominação que abarca todos os dispositivos organizados que têm como função compor os valores legítimos divergentes das instituições que adquiriram nas sociedades modernas o direito a mobilizarem autonomamente o espaço público". Compatibilizar as legitimidades dos diferentes campos é um processo tensional que institui o conceito de publicidade e, segundo Rodrigues (1990) é a origem do campo dos media caracterizado por mobilizar o debate público e responsabilizar-se pela emergência, promoção e publicização das fronteiras dos demais campos. Essa autonomização do campo obedece a imperativos lógicos e estratégicos, mobilizando indivíduos e o conjunto 
da sociedade em torno de valores comuns, fato que contraria a tendência fragmentadora dos demais campos, gerando dispositivos de percepção da realidade e constituindo a própria experiência do mundo moderno.

A necessidade dos demais campos em impor regras de comportamento com vistas ao respeito social de suas ordens e valores é um dos fatores que mantêm a permanência do campo dos media. Nas mídias tradicionais as representações são construídas de modo restrito e há um efeito irradiativo dos referentes que as produziram (espaço, tempo, linha editorial, anunciantes). No contexto midiático, a aquisição de visibilidade pública passa obrigatoriamente por este processo de mediação conhecida como a principal característica do campo dos media. Para Rodrigues "a necessidade dos demais campos de impor regras de comportamento com vistas a mobilização da sociedade para o respeito as suas ordens e valores é o fator que mantém a permanência do campo dos media" (1999, p.21).

São cada vez mais os complexos dispositivos técnicos de mediação que ajustam a nossa percepção do mundo às suas capacidades de simulação. Os governos programam as suas tomadas de decisão, os exércitos realizam as suas operações em função dos horários televisivos de maior audiência. As famílias organizam as suas refeições e as suas saídas de maneira a não perderem os seus programas televisivos favoritos. As editoras fazem depen- der as suas agendas editoriais da publicação de romances que serviram de roteiro às telenovelas e às séries difundidas nos horários de grande audiência. Os manifestantes escolhem os momentos e os locais de exibição dos seus protestos em função da presença e da localização de câmaras de televisão (RODRIGUES, 1999, p. 1).

Uma das características dos campos dos media é privar a publicidade dos que não se sujeitam às suas ordens e valores de mediação e não cumprem as regras do seu discurso, o efeito é a carência da visibilidade pública com a consequente perda da existência social das "vítimas" sociais. Hoje, podemos afirmar que, cada vez mais, a realidade se confunde com o que se torna público através da mídia de modo intermitente, confundindo-se com o próprio pulsar da vida social. Em sentido análogo, Jesús Martin Barbero (2004) caracteriza os meios não apenas como reprodutores de ideologia, mas também como ponto onde se faz e se refaz a cultura das maiorias, se comercializam formatos e se recriam narrativas mercantis com a memória coletiva.

O conceito de campo dos media corrobora a relevância das mídias tradicionais na sociedade, porém, a complexificação da teia social advinda, sobretudo, com o advento da internet não está presente em seu interior, esta abordagem é abarcada nas problematizações acerca do processo de midiatização social, que terá suas características discutidas a seguir. 


\section{O processo de midiatização}

$\mathrm{Na}$ busca pela diferenciação entre sociedade midiática e sociedade midiatizada a questão de fundo são os meios de comunicação. Certamente, hoje, a natureza do espaço público é transformada, pois, já não é mais coordenada pela representação tradicional da imprensa escrita.

O impacto da chamada "economia digital" sobre o mundo do trabalho e sobre a cultura repercute sobre as ciências sociais voltadas para o fenômeno midiático, levando-as a tentar melhor posicionamento epistemológico, no que diz respeito ao objeto e ao acompanhamento das mutações sociais provocadas pela mídia e pela realidade virtual (SODRÉ, 2006, p.19).

Estas reflexões demonstram que o tema da comunicação social está extremamente interligado com os processos sociais. A mídia é uma forma de comunicação que possui como principal característica a utilização de meios técnicos, já a midiatização pode ser considerada como uma ambiência que transpõe as características tecnológicas dos meios de comunicar, interferindo intensamente também nas formas de sociabilidade.

Conforme Braga,

a palavra "mediatização" pode ser relacionada a pelo menos dois âmbitos sociais. No primeiro são tratados processos sociais especificos que passam a se desenvolver (inteira ou parcialmente) segundo as lógicas da mídia. Aqui, pode-se falar em mediatização de instâncias da política, do entretenimento, da aprendizagem. Já em um nível macro, trata-se da midiatização da própria sociedade (BRAGA, 2007, p. 141).

Sodré (2002) pensa a midiatização como um quarto âmbito existencial, denominado bios midiático, onde a esfera de mercado predomina e traz uma qualificação cultural própria dada pelas evoluções que exigem do indivíduo a prática de novas formas de sociabilização. O ethos contemporâneo, a consciência atuante e objetivada de um grupo social, é midiatizado e comporta a mesma lógica estrutural de funcionamento da hipermídia, da qual tem a base para as interpretações simbólicas e regulação das identidades individuais e coletivas. A mídia é levada a encenar uma nova realidade humana, enquanto a internet a virtualiza. Nesse reordenamento social, os conteúdos e seus significados possuem fins mercadológicos embutidos em seus códigos, mantendo assim o sistema econômico global.

Em uma era de maturação tecnológica caracterizada pela emergência de novos valores, novos meios de interagir e comunicar configuram as formas de perceber e pensar a realidade. Os regimes de visibilidade pública não acontecem apenas pelas mídias tradicionais, mas também através de uma comunicação instantânea, simultânea e real, são esses os contornos que caracterizam o processo de midiatização.

Verón (1997) postula que a 
comunicação midiática resulta da articulação entre os dispositivos tecnológicos e as condições específicas de produção e de recepção enquanto que a midiatização surge como processo decorrente da acelerada evolução tecnológica, bem como das demandas sociais, as quais fazem com que o ser humano aspire novas formas de comunicação.

As mídias fazem parte de um campo de porosidades e complexidades no qual as questões tecnológicas e sociais são contempladas.

Um médio de comunicación social es um dispositivo tecnológico de producción-reproducción de mensages asociado a determinadas condiciones de producción y a determinadas modalidades (o prácticas) de recepción de dichos mensajes. La noción de medio de comunicación social que me parece más útil en el presente contexto debe satisfacer al critério del acceso plural a los mensages (...) esto permite definir el sector de los médios de comunicación como um mercado y caracterizar el conjunto como oferta discursiva (VERÓN,1997, p. 6-7).

Fausto Neto (2006) propõe que, embora Rodrigues (1990) reconheça a autonomia do campo dos media em agir por conta própria na tematização e publicização de informações o pesquisador português ainda considera os meios de comunicação numa posição representacional, na medida em que fazem veicular algo, cujo controle de enunciação estaria fora do seu âmbito: os outros campos sociais.
Esse fechamento dos meios em um campo caracteriza-os como instrumentos de mediação e representação dos demais campos sociais, algo que necessita ser repensado devido à configuração das mídias na atualidade.

$\mathrm{Na}$ sociedade atual onde os meios passam de atores a sujeitos centrais na vida cotidiana e as tecnologias de comunicação implantam-se vertical e horizontalmente nas instituições. Esse fenômeno nos remete a uma proposição tecnomidiática que atribui à mídia uma centralidade tanto nos processos interativos quanto na construção social em si.

Já não se trata mais de reconhecer a centralidade dos meios na tarefa de organização de processos interacionais entre os campos sociais, mas de constatar que a constituição e o funcionamento da sociedade - de suas práticas, lógicas e esquemas de codificação - estão atravessados e permeados por pressupostos e lógicas do que se denominaria a «cultura da mídia». (FAUSTO NETO, 2008, p. 92).

Portanto, estamos diante de um fenômeno situado para além das características dos meios enquanto instrumentalidades. Nele a mídia assume centralidade crescente e a sociabilidade é feita principalmente através de ligações técnicas, na qual os sujeitos estão sistematicamente conectados em novas configurações possíveis de tempo e espaço. A figura a seguir ilustra esta nova configuração da presença midiática:

A partir do esquema proposto por Verón (1997) e com base 


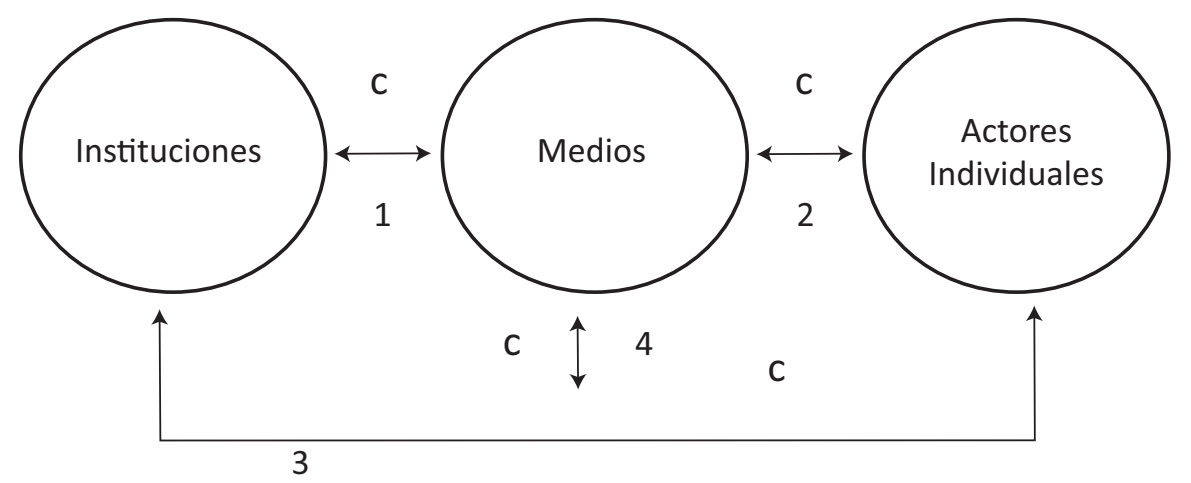

Figura 1 - Eliséo Verón (1997). Esquema para el analisis de la mediatización.

em suas afirmações ressaltamos que: os meios são instituições, porém encontram-se fora de seu círculo por possuírem funções de centralidade no espaço; os "Cs" indicam o caráter coletivo das relações de comunicação social; em $\mathrm{C} 1$ há a relação recíproca das instituições com os meios; em C2 há a relação recíproca dos indivíduos com os meios; em C3 há a relação das instituições com os indivíduos; no entanto, apesar de ser uma relação sem os meios de comunicação em uma extremidade, todas as relações sofrem influência dos mesmos, tendo em vista a ambiência midiatizada, como pode-se visualizar em C4.

Essa cultura constituída, sobretudo pelo mercado e meios de comunicação traz novas referências para a rotina dos indivíduos, o que implica uma nova condição antropológica. Para Sêga (2008) os indivíduos apóiam-se nas ideologias transmitidas pelos atuais meios de comunicação de massa, incluindo a internet, para construir a realidade simbólica. Estas mesmas ideologias são articuladas de modo a realizar a interação entre o homem e a sociedade de consumo, passando a buscar uma identificação, uma aproximação, enfim uma intera- ção com o universo em que se encontra.

Ao buscar compreender o papel do jornalismo na contemporaneidade Soster (2006) aponta uma diferença substancial entre a tecnologia que se inaugura em 1850 , quando surgiu a primeira impressão rotativa e a surgida a partir de 1995, quando os jornais migram para a internet. Para o autor, a primeira fundamentalmente media relações e processos enquanto que a segunda, midiatiza estas mesmas relações e processos e desloca para si o vetor do poder, transformando, substancialmente, sentidos seculares.

Para Martino (2006), na sociedade contemporânea a comunicação sai do viés técnico, torna-se o centro de referência para a vida social e instala uma movimentação de valores que interferem sobremaneira na tomada de decisão de sujeitos e instituições. Para tanto, os sistemas de comunicação estabelecem preceitos que não apenas orientam nossas ações, mas trabalham para que incorporemos à nossa representação de mundo o estado atual de um sistema social em perpétua e intensa mudança.

O cenário da midiatização social ocasiona diversas transfor- 
mações na esfera dos estudos das teorias da comunicação, porém é importante salientar que ainda existem, e por vezes até persistem, estudos da comunicação social com perspectivas instrumentais e funcionalistas. Os modelos estímulo-resposta e os conceitos da teoria matemática, por exemplo, fazem parte de um paradigma que precisa ser renovado, na medida em que as tecnologias desandam seu desenvolvimento e consolidam a participação nos processos de comunicação. Haja vista que a expressão 'processo' não fazia parte da maioria dos paradigmas anteriores.

As mídias inserem-se nas rotinas dos sujeitos e das instituições sociais, pois são fenômenos que transcendem aos meios e às mediações e encontram-se no interior dos processos dos demais campos sociais, influenciando suas lógicas a partir de suas dinâmicas tecno-discursivas. Conforme Fausto Neto (2006, p. 9) pontua, "as operações de midiatização afetam largamente práticas institucionais que se valem de suas lógicas e de suas operações para produzir as possibilidades de novas formas de reconhecimento nos mercados discursivos". Hoje, os conceitos e evoluções concernentes ao campo dos media e ao processo de midiatização social ainda são pouco problematizados na área da comunicação social, eles encontram-se, sobretudo atrelados apenas à esfera das tecnologias.

Portanto, um desafio se instala e manifesta a necessidade de reflexões teóricas sobre as processualidades e fenômenos midiáticos contemporâneos, teoricamente mídias tradicionais e contemporâneas coexistem no espaço público, cada qual com suas regras e valores discursivos, porém, a atualidade mostra a existência de um nível de afetação entre elas que pode colaborar para que as ordens e regras particulares a cada uma sejam transformadas. Assim, é pertinente aos estudiosos da comunicação a busca pelo entendimento dos modos como a ambiência midiatizada interfere nas lógicas de funcionamento dos meios de comunicação tradicionais como a televisão, o rádio e os impressos.

\section{Convergência midiática e produtos contemporâneos}

Os autores supracitados nos apresentam visões sobre como o desenvolvimento das tecnologias e dos meios de comunicação afetaram a sociedade. Isso foi irreversível tanto para os sujeitos quanto para as instituições, pois, ocasionou a potencialização da globalização e a elevação da mídia a uma condição de centralidade social.

A partir de então, os desenvolvimentos tecnológicos colaboram para um maior alcance e relevância das mídias, acontecimento que tem consequência direta nos modos de percepção e atuação dos sujeitos sobre a realidade. Assim, o espaço público adquire uma nova configuração na qual predomina o que podemos denominar de "Cultura da Convergência”, para Jenkins (2008) essa cultura fundamentase em conceitos como a convergência midiática, a inteligência coletiva e a cultura participativa.

Segundo o autor, a característica principal da era de convergên- 
cia midiática seria o cruzamento de mídias alternativas e de massa e a hibridização de conteúdos de novas e velhas mídias que ocasionam outras formas de relações entre as tecnologias, indústria, mercados, gêneros e públicos.

Já a inteligência coletiva é tomada sob a perspectiva do consumo, visto como uma nova fonte de poder, no qual predomina a economia afetiva guiada diretamente pela participação dos públicos, a partir das possibilidades midiáticas, eles tornam-se importantes catalizadores nas decisões de audiência e de compra. Esses fenômenos formam uma cultura participativa que caracteriza o comportamento do consumidor midiático contemporâneo, cada vez mais distante da condição de receptor passivo.

Conforme Kerckhove (1997) a convergência midiática aponta para o surgimento de novas formas de consciência e mudanças nas estruturas sociais;

Enquanto a TV fornecia uma espécie de espirito coletivo para toda a gente, mas sem qualquer contribuição individual, os computadores eram espíritos privados sem contribuições coletivas. A convergência de ambos oferece uma possibilidade nova, sem precedentes, a de ligar indivíduos com as suas necessidades pessoais a mentes colectivas. Esta nova situação é profundamente criadora de novos poderes; tem repercussões sociais, políticas e econômicas. Irá acelerar as mudanças e adaptações na cena geopolítica assim como na sensibilidade privada de todos (KERCKHOVE, 1997, p. 89-90).
Apesar da presença do contexto convergente, ainda encontram-se algumas perspectivas epistemológicas que levam em conta apenas um dos lados da questão, dando destaque apenas ao âmbito tecnológico ou somente ao aspecto social. Neste sentido, é adequado ao campo uma construção teórica a partir de uma perspectiva sócio-técnica que leve em conta a integração dos meios de comunicação à organização social contemporânea. É necessário traçar uma nova geografia do campo da comunicação, que leve em conta a ampliação de possibilidades de estudos trazidas pela afetação entre sociedade e tecnologia.

Nesse processo tanto a análise dos meios quanto a análise dos comportamentos dos sujeitos se entrecruzam e estabelecem a cultura e os fenômenos de comunicação social. Hoje não é possível analisar a comunicação sem considerar os dois, pois os próprios meios são originados de comportamentos e situações sociais do ser humano. Os meios modificam os comportamentos e os comportamentos modificam os meios em um processo cíclico e constante, daí a denominação sócio-técnico.

A amplitude dos fenômenos que constituem o campo da comunicação social possibilitam diversas investigações, estas, porém, nem sempre visam a complementaridade frente ao que já existe em termos teóricos, o que, por vezes quebra o avanço epistemológico necessário. Em contraponto, estamos diante de algumas pesquisas contemporâneas que objetivam propor ou investigar atualizações de modelos de épocas passadas frente à 
mutação tecnológica característica da sociedade complexa como, por exemplo, a re-significação do líder de opinião no modelo do two-step flow of communication a partir das características da midiatização social que transforma os modelos de influência e os efeitos dos discursos (DUARTE e AIRES, 2008), a ruptura das regências lineares e deterministas que atravessam discurso, técnica e cultura, domínios relevantes para o campo da comunicação (FERREIRA, 2008) ou a cultura da mídia e o triunfo do espetáculo na contemporaneidade (KELLNER, 2006).

Considera-se que deveria prevalecer nas pesquisas científicas a consciência de que a comunicação social é gerenciada e produzida por sujeitos simbólicos que utilizam os meios de comunicação para interagir e expressar seus pensamentos e opiniões através de mensagens. Assim, enxergar a sociedade a partir das mídias é o objeto de interesse da comunicação, num contexto de complexificação da teia social (MARTINO, 2006). A transformação de uma esfera pública centrada na representação em que sujeitos e instituições sociais buscavam visibilidade através da mídia para um espaço público de tecnointerações entre mídia, instituições e sujeitos opera novas regras de inteligibilidade. A instalação desta ambiência midiatizada generaliza a construção de novas práticas de sentido diretamente atravessadas por fluxos midiáticos que remodelam os vínculos sociais entre meios de comunicação e sujeitos. A convergência midiática é um dos componentes que traduz as mudanças nas formas de relacionamento entre sujeitos e meios de comunicação, o processo de mediação que acontecia de forma mais objetiva e representacional agora está repleto de estratégias que trazem implicações consideráveis no modo como apreendemos os fatos da realidade, trabalhamos, consumimos, participamos na cultura, política e sociedade.

Hoje podemos reconhecer um 'movimento inverso' dos sistemas representacionais que têm na convergência tecnológica a principal responsável, pois essa permitiu a rearticulação dos processos de visibilidade a partir da interação entre produtores e receptores de discursos e a produção dos sujeitos que antes tinham poucas alternativas de visibilidade diante das mídias clássicas. "A midiatização institui um novo «feixe de relações», engendradas em operações sobre as quais se desenvolvem novos processos de afetações entre as instituições midiáticas e os atores sociais" (FAUSTO NETO, 2008, p. 96).

Assim, o estudo dos conhecimentos gerados em torno dos aspectos teórico-epistemológicos dessas afetações é fundamental para o acompanhamento crítico dos problemas que emergem com a chamada Sociedade da Informação. Alguns fatos recorrentes na esfera das mídias levam-nos a observância e classificação de fenômenos contemporâneos da comunicação, tomemos como exemplo um telejornal, caracterizado como um produto tradicional, no qual emissores e receptores podem ser considerados como donos de posições definidas onde um emite e o outro recebe as mensagens.

A edição do dia 31 de agosto 
de 2009 do Jornal Nacional traz algumas características que demonstram certas afetações que a instância das mídias tradicionais sofre na atualidade. A transformação dos apresentadores em atores, relevando as notícias ao segundo plano, torna-se evidente, conforme percebemos na chamada inicial: "Fátima Bernardes e William Bonner mostram como ficou o novo cenário do Jornal Nacional em comemoração ao aniversário de 40 anos no ar".

As questões referentes a modernização e acompanhamento das tecnologias parecem sobressair, conforme apresenta o portal do Jornal Nacional na internet:

Nas comemorações dos seus 40 anos no ar, o JN ganhou uma cara nova. Mais moderno e mais bonito. Acompanhando as evoluções tecnológicas, o cenário ganhou inovações como um telão onde será projetado o mapa mundial, que ganha movimento. No fundo da redação, uma série de televisões de tela plana vão apresentar imagens relacionadas às reportagens ${ }^{l}$.

Percebe-se que as metodologias de produção são reconfiguradas, além das questões da espetacularização de programas que, inicialmente, não possuíam este viés. As possibilidades advindas com as tecnologias interferem nas lógicas destes ambientes, a construção de um site do programa exibido nas mídias tradicionais, por exemplo, demonstra o uso da convergência e origina a capacidade de busca pelo contato e interatividade com o receptor. A convergência midiática confere um outro status às audiências, com mais possibilidades de interação com os sistemas de produção. Estratégias como a presença de enquetes, a busca de opinião sobre reportagens, o acesso às reportagens em destaque antes do programa ir ao ar, a exibição das notícias mais acessadas, os arquivos e a disponibilidade do programa na íntegra através da rede são opções que possibilitam níveis de acesso e de participação inconcebíveis, até então.

Além disso, as repercussões sobre as notícias veiculadas nas mídias tradicionais e exibidas em redes sociais como orkut e twitter, a postagem de vídeos em sites como youtube, ou ainda comentários em blogs e sites pessoais podem ser considerados sistemas de resposta (BRAGA, 2006) que interferem nas lógicas de produção e nos moldes como a informação desdobra-se nas mídias tradicionais.

A publicidade também pode servir como um objeto ilustrativo da afetação entre mídias, uma vez que seu sistema de visibilidade tradicional transforma-se e coloca os receptores cada vez mais próximos dos produtos. $\mathrm{O}$ acesso dos consumidores sai da instância representacional e parte para uma realidade virtual e interativa. A lógica da publicidade sofre afetações a partir de mensagens veiculadas em novos dispositivos, um exemplo significativo é o vídeo, postado no youtube, pela adolescente Sthefany, do Piauí, com a canção "Eu sou Sthefany - No meu Cross Fox"2 o vídeo é uma versão da música de Vanessa Carlton e ganhou proporções inacreditáveis como mais de 500 mil acessos em poucos dias, isso garantiu não apenas a fama para
1 - Informações disponíveis em www.jornalnacional.globo. com. Acesso em 31 ago 2009.

2 - Vídeo disponível em http://www.youtube.com/ watch?v=bMK_rwcTP78 
a adolescente como também a publicidade para a empresa de automóveis em questão. $\mathrm{O}$ vídeo extrapolou a esfera da internet e foi exibido em programas da TV aberta como o "Programa do Gugu" e "Fantástico", mas o ápice da afetação entre mídias tradicionais e contemporâneas foi a estreia da cantora Sthefany no programa "Caldeirão do Huck", no dia 27 de junho de 2009 ela participou do programa, cantou o seu hit e ao final foi presenteada pela Volskswagem com um Cross Fox.

Estes exemplos de afetações que a convergência midiática proporcionou ao jornalismo e à publicidade tradicionais buscam demonstrar que estão em andamento transformações irreversíveis nos modos de fazer e pensar a comunicação.

\section{Considerações finais}

Até poucos anos atrás, a competência de produção e enunciação de discursos era creditada apenas à instância producional, porém, os modelos assimétricos de comunicação não se sobressaem mais. $\mathrm{O}$ presente artigo buscou elucidar conceitos com vistas a complementar algumas abordagens sobre a configuração midiática advindas com os desenvolvimentos tecnológicos e a emergência de novos dispositivos de comunicação.

É possível afirmar que as questões contemporâneas refletem-se e problematizam-se no campo dos media, porém sua abordagem teórica referencia apenas o vetor representacional, fato insuficiente para a lógica da midiatização social na qual atuamos hoje. Assim, apesar dos meios serem os grandes protagonistas e possuírem legitimidade para superintender a experiência de mediação torna-se eminente a necessidade de conceituações sobre acontecimentos como as transformações nos sistemas de produção tradicionais, a convergência midiática, o poder exacerbado das imagens, os níveis de consumismo e dedicação dos sujeitos às mídias, a falta de distinção entre real e ficção, a interatividade absoluta e a pouca autoreflexividade diante das mídias.

Entende-se que o processo de midiatização ocasiona e delineia formas de interações intermidiáticas difíceis de serem imaginadas antes do advento da internet, por isso é pertinente defendermos que o pensar comunicacional necessita ser revisto em busca da atualização de conceitos, a partir dos acontecimentos vivenciados na atualidade.

Logicamente, a autonomia e poder de mediação do campo dos media permanecem e podem ser considerados um diferencial para a expansão de novas operações interativas com os receptores. Mas a realidade mostra a articulação de relações entre mídias tradicionais e reticulares fatores que ocasionam inúmeras transformações para a área, assim, este artigo busca consolidar-se como um pequeno passo em busca da edificação de conceitos e teorias que abarquem a complexidade dos fenômenos midiáticos contemporâneos. 


\section{Referências}

AUGÉ, Marc. Sobremodernidade: do mundo tecnológico de hoje ao desafio essencial do amanhã. In: MORAES, Dênis de (org). Sociedade midiatizada. Rio de Janeiro: Mauad, 2006.

BARBERO, J. M, Globalização comunicacional e transformação cultural In: MORAES, Dênis de. (org). Por uma outra comunicação. Rio de Janeiro: Record, 2004.

BAUMAN, Zygmunt. Modernidade líquida. Rio de Janeiro: Jorge Zahar Editor, 2001.

BRAGA, J. L. Mediatização como processo interacional de referência. In: MÉDOLA, Ana Sílvia L., ARAÚJO, Denise Correia, BRUNO, Fernanda (Org). Imagem, visibilidade e cultura midiática. Livro da XV Compós. Porto Alegre: Sulina, 2007.

BRAGA, José Luiz. A sociedade enfrenta sua mídia: dispositivos sociais de crítica midiática. São Paulo: Paulus, 2006.

DUARTE, Pedro, Russi; AIRES, Lauro. Re-significação dos Líderes de Opinião pelo ambiente mediático. In: CONGRESSO BRASILEIRO DE CIÊNCIAS DA COMUNICAÇÃO, 31, 2008. Natal, RN. Anais... Natal, UFRN.

FAUSTO NETO, Antonio. Midiatização, prática social-prática de sentido. SEMINÁRIO SOBRE MIDIATIZAÇÃO, REDE PROSUL, Anais... São Leopoldo: UNISINOS, 2006.

. Fragmentos de uma «analítica» da midiatização. Revista MATRIZes n. 2. abril, 2008.

FERREIRA, Giovandro Marcus. O desenvolvimento das teorias da comunicação: para além do determinismo comunicacional. In: $\mathbf{C O N}-$ GRESSO BRASILEIRO DE CIÊNCIAS DA COMUNICAÇÃO, 31, 2008. Natal, RN. Anais... Natal, UFRN.

FOUCAULT, Michel. Vigiar e punir. Petrópolis: Vozes, 1986.

JENKINS, Henry, Cultura da Convergência. São Paulo: Aleph, 2008.

KERCKHOVE, Derrick. A Pele da Cultura. Lisboa: Relógio D' Água, 1997.

KELLNER, Douglas. Cultura da Mídia e triunfo do espetáculo. In: MORAES, Dênis de (org). Sociedade midiatizada. Rio de Janeiro: Mauad, 2006. 
LYON, David. Pós-modernidade. São Paulo: Paulus, 1998.

LYOTARD, Jean-François: O pós-moderno. Rio de Janeiro: Olympio Editora. 1990

MARTINO, Luiz C. Abordagens e Representação do Campo Comunicacional. Comunicação, Mídia e Consumo (São Paulo), v. 3, p. 33-54, 2006.

MARTINO, L. C. A Revolução Mediática: a comunicação na Era da simulação tecnológica. Razón y Palabra, México, v. 50, 2006.

RODRIGUES, Adriano Duarte. Estratégias da Comunicação. Questão Comunicacional e Formas de Sociabilidade. Lisboa: Presença, 1990.

Experiência, modernidade e campo dos media. In: BOCC Biblioteca On-line de Ciências da Comunicação. V. 1, p. $1-32,1999$

SODRÉ, Muniz. Antropológica do Espelho. Por uma teoria da comunicação linear e em rede. Petrópolis, RJ: Vozes, 2002.

Eticidade, campo comunicacional e midiatização. In: MORAES, Dênis de (org). Sociedade midiatizada. Rio de Janeiro: Mauad, 2006.

SOSTER, D. A. Sobre midiatização, mediação, poder e jornalismo. In: BOCC. Biblioteca On-line de Ciências da Comunicação, v. 1, p. 1-9, 2006.

VERÓN, Eliseo. Esquema para el análisis de la mediatización. In: Diálogos de la Comunicación. Lima: Felafacs, 1997.

WOLTON, Dominique. Elogio do grande público. São Paulo: Ática, 1996.

Data do Recebimento: 05/08/2009

Data do Aceite: 01/09/2009 